\title{
Mapping Global Crop Exposure to Extremely High Temperature
}

\author{
Yaojie Yue, Peng Su, Yuan Gao, Puying Zhang, Ran Wang, \\ Anyu Zhang, Qinghua Jiang, Weidong Ma, Yuantao Zhou, \\ and Jing'ai Wang
}

\section{Introduction}

The increasing temperature with global warming will have great impacts on major cereal crop cultivation (Peng et al. 2004; Fahad et al. 2019). Among various impacts, the crop exposure to extremely high temperature, which is based on the land suitability for crop cultivation, may ultimately pose a great threat to food security.

The crop disaster exposure is one of the primary drivers of food system instability (Change 2018), and its response to climate change is critical to understanding the impact of climate change on food security. Recent studies have provided evidence for changes in the yield of major cereal crops due to disaster exposure and identified significant impacts of climate change globally, either at the country level or at the $0.5^{\circ}$ grid level (Osborne and Wheeler 2013; Iizumi and Ramankutty 2016). However, from the perspective of disaster exposure, research on crop exposure to certain hazards

Authors: Yaojie Yue, Peng Su, Yuan Gao, Puying Zhang, Ran Wang, Anyu Zhang, Qinghua Jiang, Weidong Ma, Yuantao Zhou, Jing'ai Wang

Map Designers: Yichen Li, Qingyuan Ma, Yuanyuan Jing, Jing'ai Wang, Ying Wang.Language Editor: Tao Ye, Peng Su.

Y. Yue $\cdot$ Y. Gao - P. Zhang · R. Wang $\cdot$ A. Zhang $\cdot$ Q. Jiang $\cdot$ J. Wang $(\bowtie)$

Key Laboratory of Environmental Change and Natural Disaster of Ministry of Education, Faculty of Geographical Science, Beijing Normal University, Beijing, 100875, China

e-mail: jwang@bnu.edu.cn

P. Su $\cdot$ W. Ma $\cdot$ Y. Zhou

School of Geographic Science, Qinghai Normal University,

Xining, 810008, China

J. Wang

State Key Laboratory of Earth Surface Processes and Resource

Ecology, Beijing Normal University, Beijing, 100875, China (e.g., extreme heat) with the changes of climate and social conditions is still lacking.

As an important part of the atlas, the maps of global crop exposure to extremely high temperature are intended to evaluate the changes in the global staple crop yield risk from three aspects -mean yield, interannual yield variability, and lower extreme yield-under the RCP2.6-2030s, RCP2.6-2050s, RCP4.52030s, RCP4.5-2050s, RCP8.5-2030s, and RCP8.5-2050s scenarios. The crop yield risk was measured by multi-model ensemble (MME) simulation using global high spatial resolution $\left(0.25^{\circ}\right)$ climate forcing data. To enable such MME simulation, the development of emulators of global gridded crop models (GGCM) is required (Lobell and Burke 2010; Holzkämper et al. 2012; Oyebamiji et al. 2015; Raimondo et al. 2020). The present results may provide crucial information for climate risk assessment and effective adaptations.

\section{Method}

\subsection{Wheat Exposure Calculation}

The quantification process of wheat exposure to extreme high-temperature hazard is as follows (Jiang et al. 2019): A high-temperature day is recorded when the maximum temperature of the current day reaches or exceeds $30^{\circ} \mathrm{C}$, and if this lasts for 3 days or more, it is recorded as a heatwave event (Deng et al. 2009; Chen et al. 2016).

The high-temperature days (HD) refer to the accumulation of total high-temperature days of heatwave events in each grid. The calculation formula is as follows:

$$
\mathrm{HD}=\sum_{i=1}^{n} D_{i}
$$


where $n$ refers to the frequency of heatwaves and $D i$ refers to the days corresponding to the $i$ th heatwave event.

Estimating the intensity of the heatwave hazard impacts on wheat involves first calculating the intensity $(I)$, which represents the daily maximum temperature exceeding the temperature threshold $\left(30^{\circ} \mathrm{C}\right)$ of each high-temperature day within heatwave events and for each grid; then, we sum up all Is. The details of this calculation are as follows:

$$
\begin{gathered}
\mathrm{HI}=\sum_{d_{\mathrm{h}}}^{d_{\mathrm{m}}} I \\
I=\left\{\begin{array}{c}
0 T_{\text {max }}<T_{\mathrm{h}} \\
T_{\text {max }}-T_{\mathrm{h}} T_{\text {max }} \geq T_{\mathrm{h}}
\end{array}\right.
\end{gathered}
$$

where $d_{\mathrm{h}}$ and $d_{\mathrm{m}}$ represent the heading period and mature period of wheat, respectively; $T_{\max }$ represents the daily maximum temperature; $I$ represents the daily temperature ${ }^{\circ}$ C) exceeding the temperature threshold during heatwave events; and $T_{\mathrm{h}}$ represents the high-temperature threshold.

The extreme high-temperature exposure of wheat is calculated as follows: The exposure range of wheat is the spatial superposition of the distribution range of wheat and the hazard range, and the areal value in the range represents the exposure value, which is the annual wheat harvest area.

\subsection{Rice Exposure Calculation}

The quantification process of rice exposure to extreme high-temperature hazard is as follows: A high-temperature event is recorded when the maximum temperature of the current day reaches or exceeds $30{ }^{\circ} \mathrm{C}$ (Melillo et al. 1995; Janetos 1997). The accumulative high-temperature stress of high-temperature events during the growth period (GHTS) was used as the high-temperature hazard intensity. The calculation process can be divided into two steps: (1) according to the abovementioned high-temperature standard, determine the high-temperature event and calculate the high-temperature stress (HTS) of the day, and then estimate the GHTS by calculating the total HTS during the whole growth period (Eqs. 4 and 5).

$$
\begin{aligned}
& \mathrm{HTS}_{i}=\left\{\begin{array}{c}
0 T_{i} \geq 30^{\circ} \mathrm{C} \\
1-\sin \left[\frac{\pi}{2} \times\left(\frac{T_{i}-T_{\mathrm{b}}}{T_{\mathrm{o}}-T_{\mathrm{b}}}\right)\right] T_{i} \geq 30^{\circ} \mathrm{C}
\end{array}\right. \\
& \mathrm{GHTS}=\sum_{i=1}^{n} \mathrm{HTS}_{i}
\end{aligned}
$$

where $T i$ is the daily average temperature of the $i$ th high-temperature event during the growth period; $T \mathrm{~b}$ is the base temperature during the growth period; To is the optimum temperature during the growth period; $n$ is the frequency of high-temperature events during the growth period; and HTS $i$ is the daily high-temperature stress value of the $i$ th high-temperature event.

The extreme high-temperature exposure of rice is calculated as follows: The exposure range of rice is the spatial superposition of the distribution range of rice and the hazard range, and the areal value in the range represents the exposure value, which is the annual rice harvest area.

\subsection{Maize Exposure Calculation}

Maize exposure calculation applies the same method as rice exposure calculation. A high-temperature event is recorded when the maximum temperature of the current day reaches or exceeds $37{ }^{\circ} \mathrm{C}$ (Melillo et al. 1995; Janetos 1997). The accumulative high-temperature stress of high-temperature events during the growth period (GHTS) was used as the high-temperature hazard intensity.

The extreme high-temperature exposure of maize is calculated as follows: The exposure range of maize is the spatial superposition of the distribution range of maize and the hazard range, and the areal value in the range represents the exposure value, which is the annual maize harvest area.

\section{Results}

\subsection{Latitudinal Distribution of Crop Exposure to High Temperature}

The latitudinal distributions of the exposure of the three crops to high temperature in the historical period (red bar) and the RCP8.5-SSP3 scenario (medium term) (blue bar) are shown in Fig. 1.

During the two study periods, the exposures of the three crops are mainly concentrated in the northern hemisphere. The most important areas for wheat, rice, and maize exposure to extreme high temperature are between $40^{\circ} \mathrm{N}-50^{\circ} \mathrm{N}$, $20^{\circ} \mathrm{N}-30^{\circ} \mathrm{N}$, and $40^{\circ} \mathrm{N}-50^{\circ} \mathrm{N}$, respectively. The comparison of the exposure areas in the two periods shows that under the RCP8.5-SSP3 scenario, the exposure areas of the three crops in the northern hemisphere will move to higher latitudes and the exposure areas of rice and maize will have a significant increase. 
Fig. 1 Latitudinal distribution of the exposure of wheat, rice, and maize to extreme high temperature (unit: million ha)
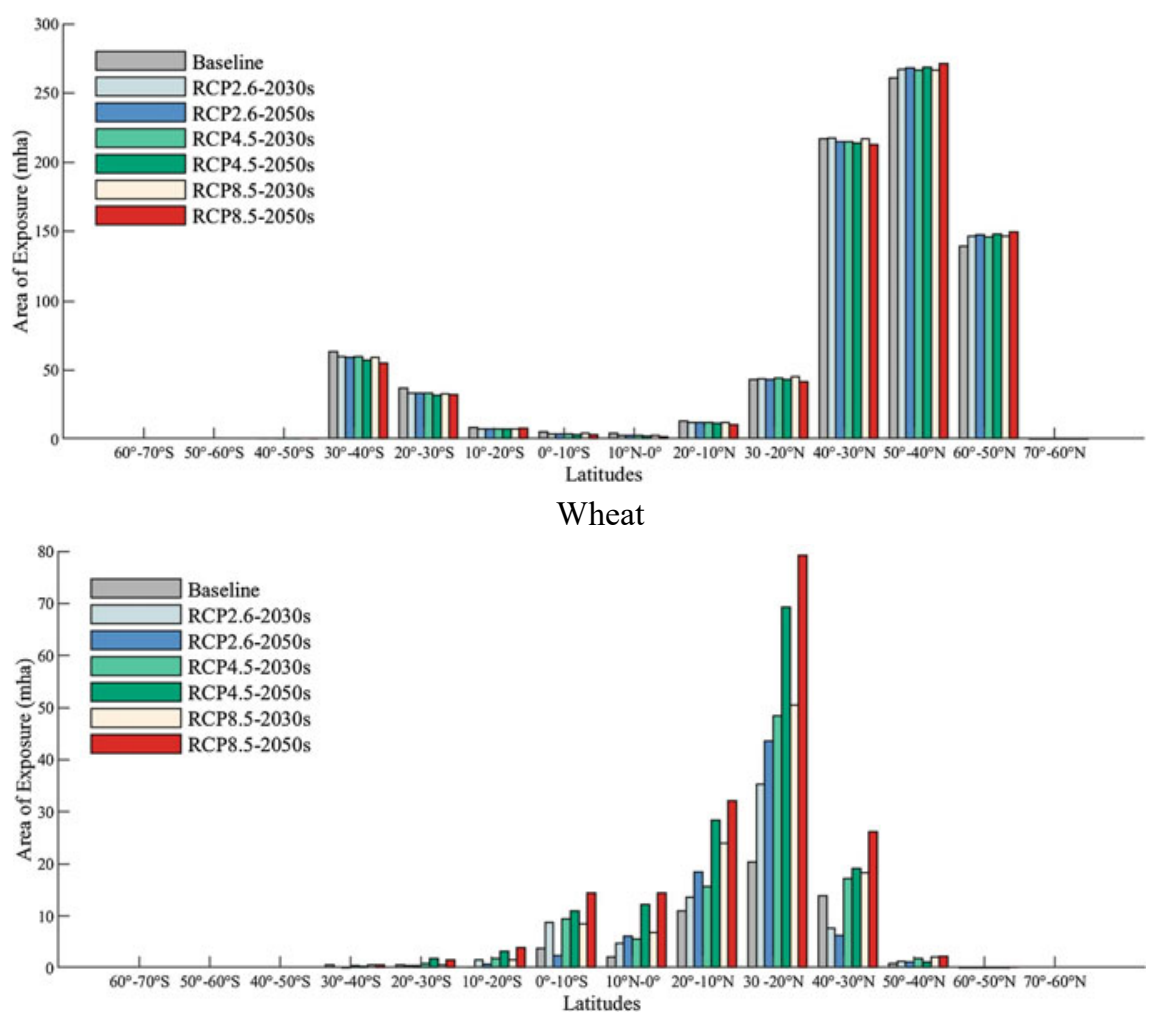

Rice

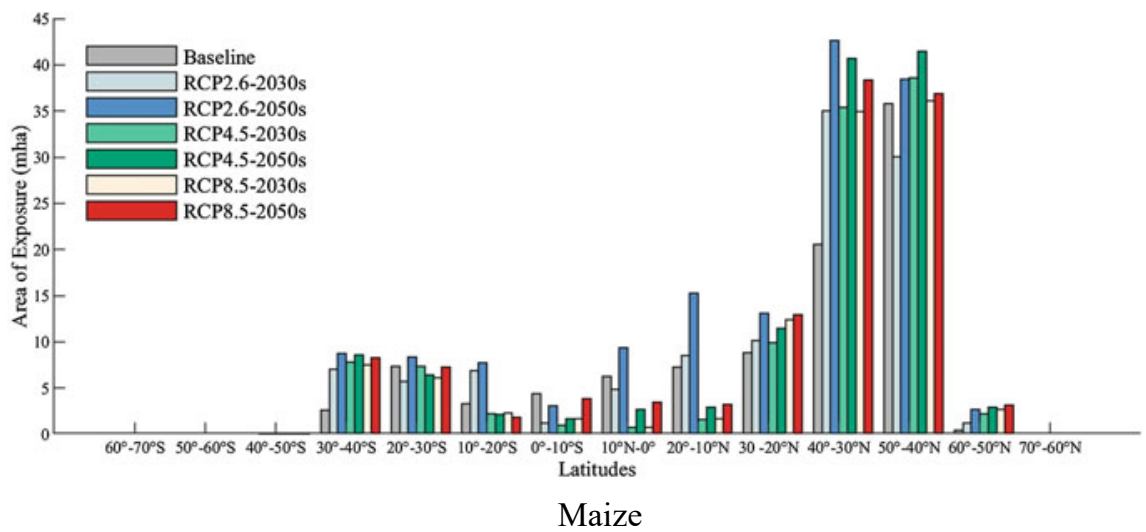

\subsection{Countries Distribution of Crop Exposure to High Temperature}

Figure 2 shows the ranking of the top 20 countries based on the statistics of the area of crop exposure to high temperature in each country in the historical period and under the RCP8.5-SSP3 scenario.

In both periods, the United States' wheat exposure area ranks the highest, followed by China. The rice exposure area of India ranks the highest, and China's rice exposure area is the second largest. The maize exposure area of the United States ranks the highest, and China's maize exposure area is the second largest. Under the RCP8.5-SSP3 scenario, the exposure area of all crops in China will increase, and the exposure area of rice is about three times that of the historical period. It indicates that China will be seriously exposed to extreme high temperature in the future, and the country should be prepared to prevent risks and reduce losses. 
Fig. 2 Ranking of the top 20 countries by the area of crop exposure to extreme high temperature (unit: million ha)
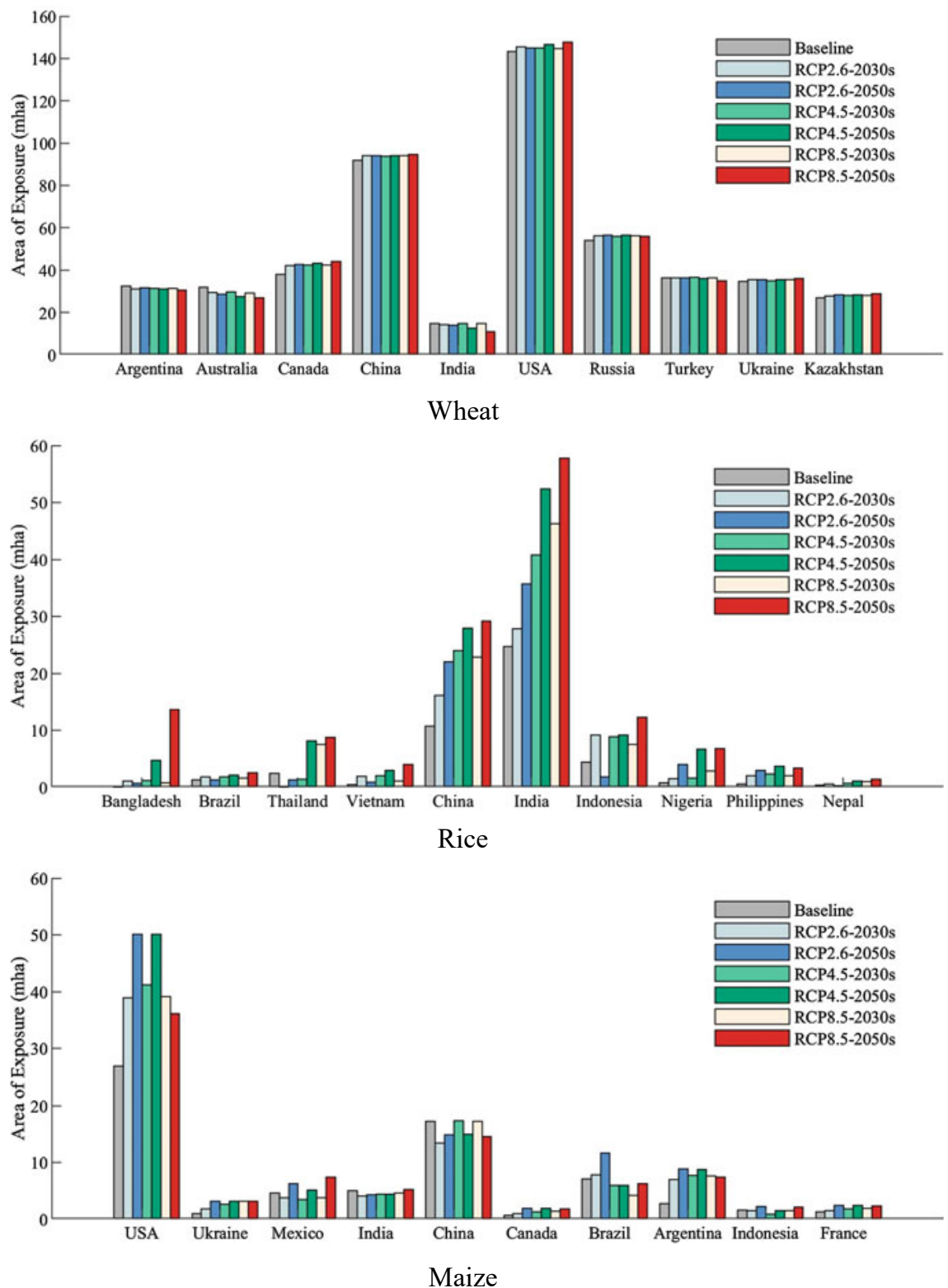


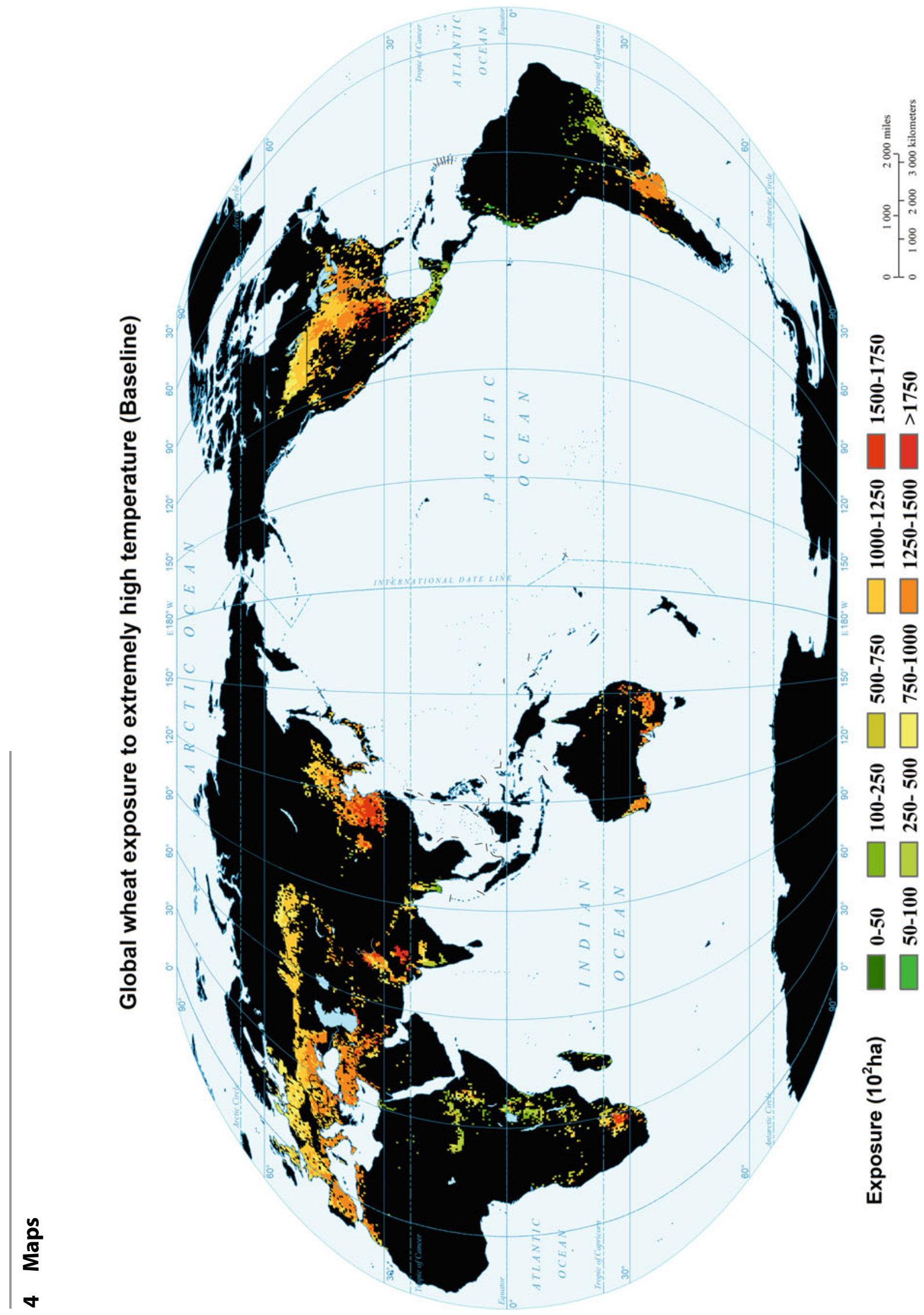


Global wheat exposure to extremely high temperature (2030s, RCP2.6-SSP1)

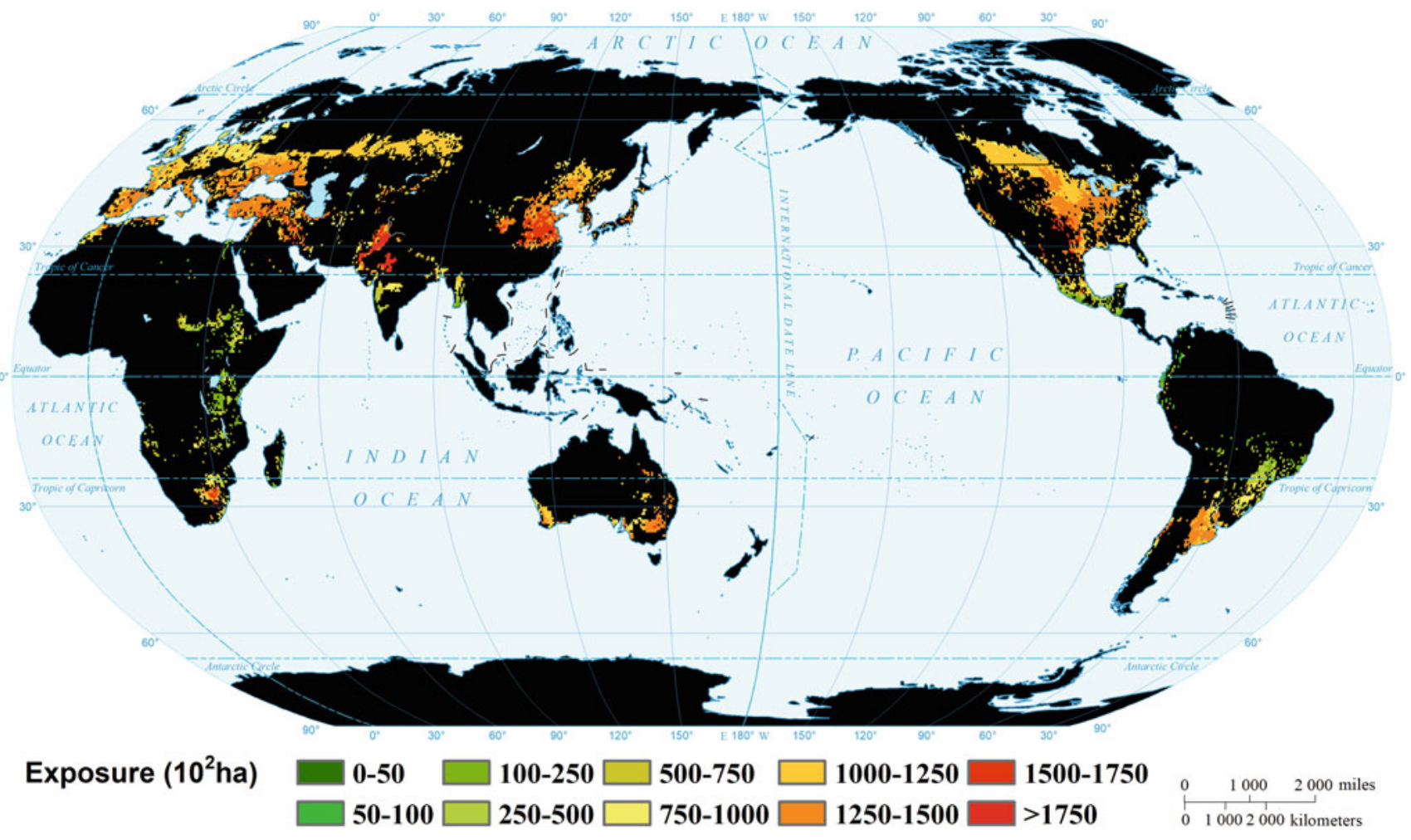

Global wheat exposure to extremely high temperature (2030s, RCP4.5-SSP2)

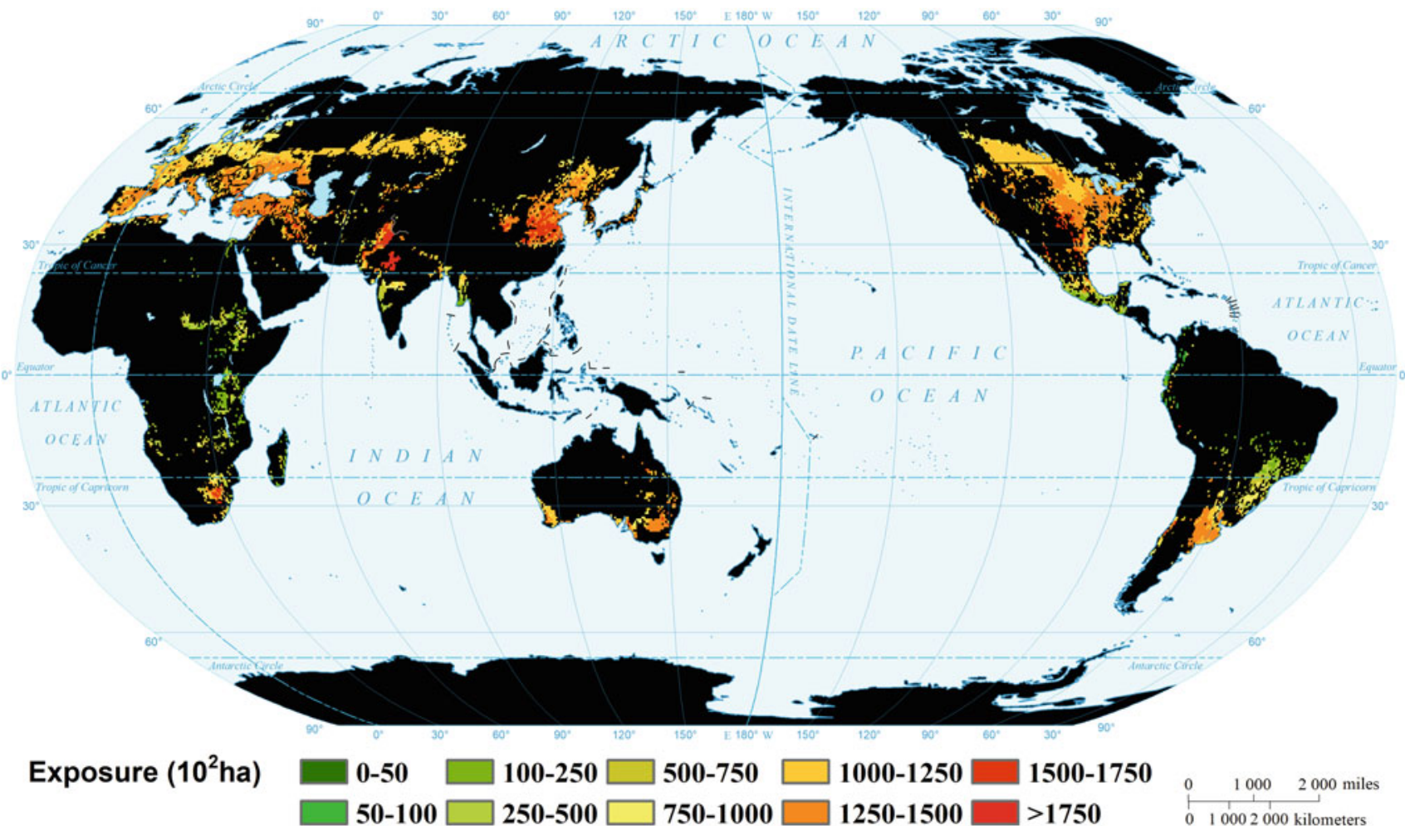


Global wheat exposure to extremely high temperature (2030s, RCP8.5-SSP3)

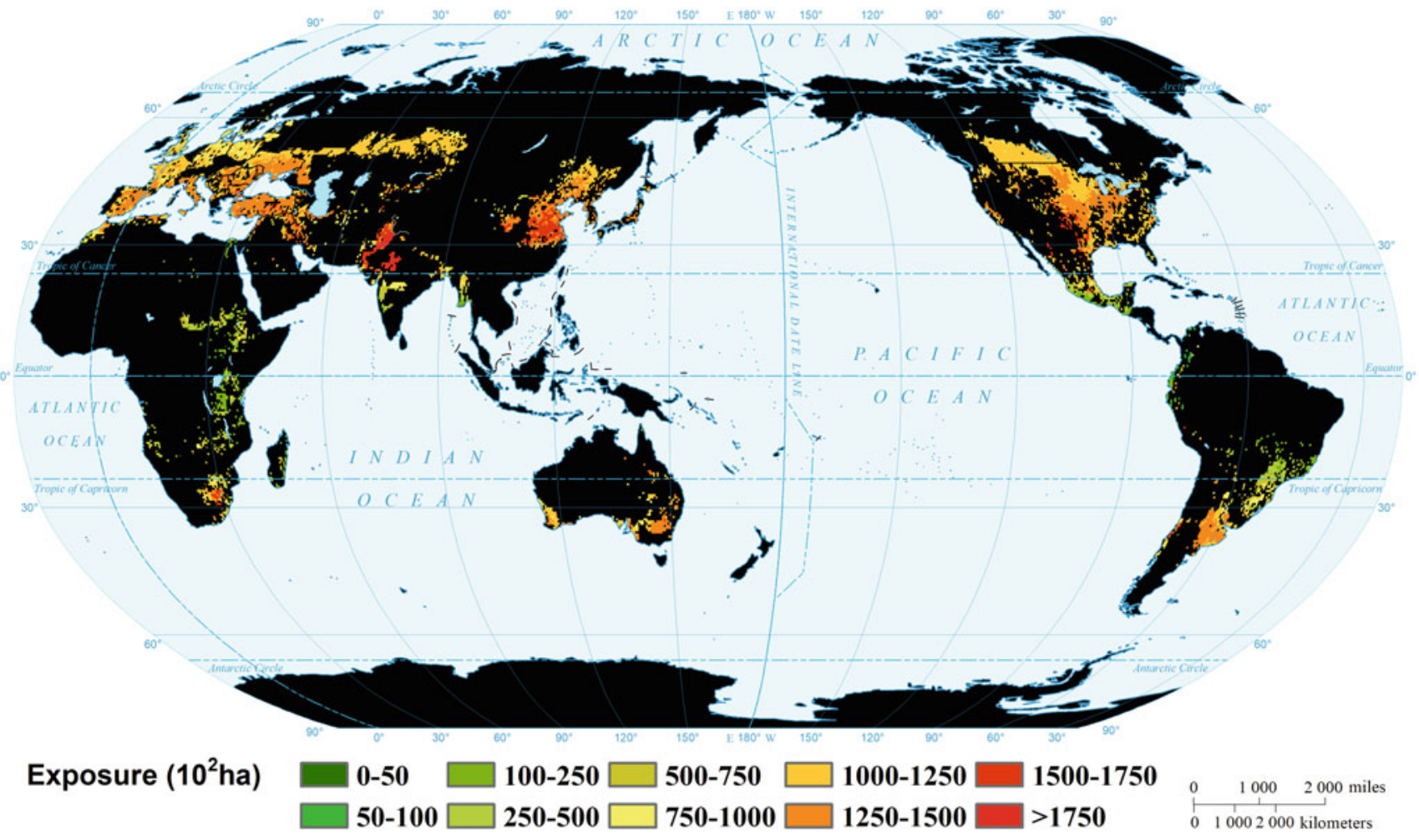

Global wheat exposure to extremely high temperature (2050s, RCP2.6-SSP1)

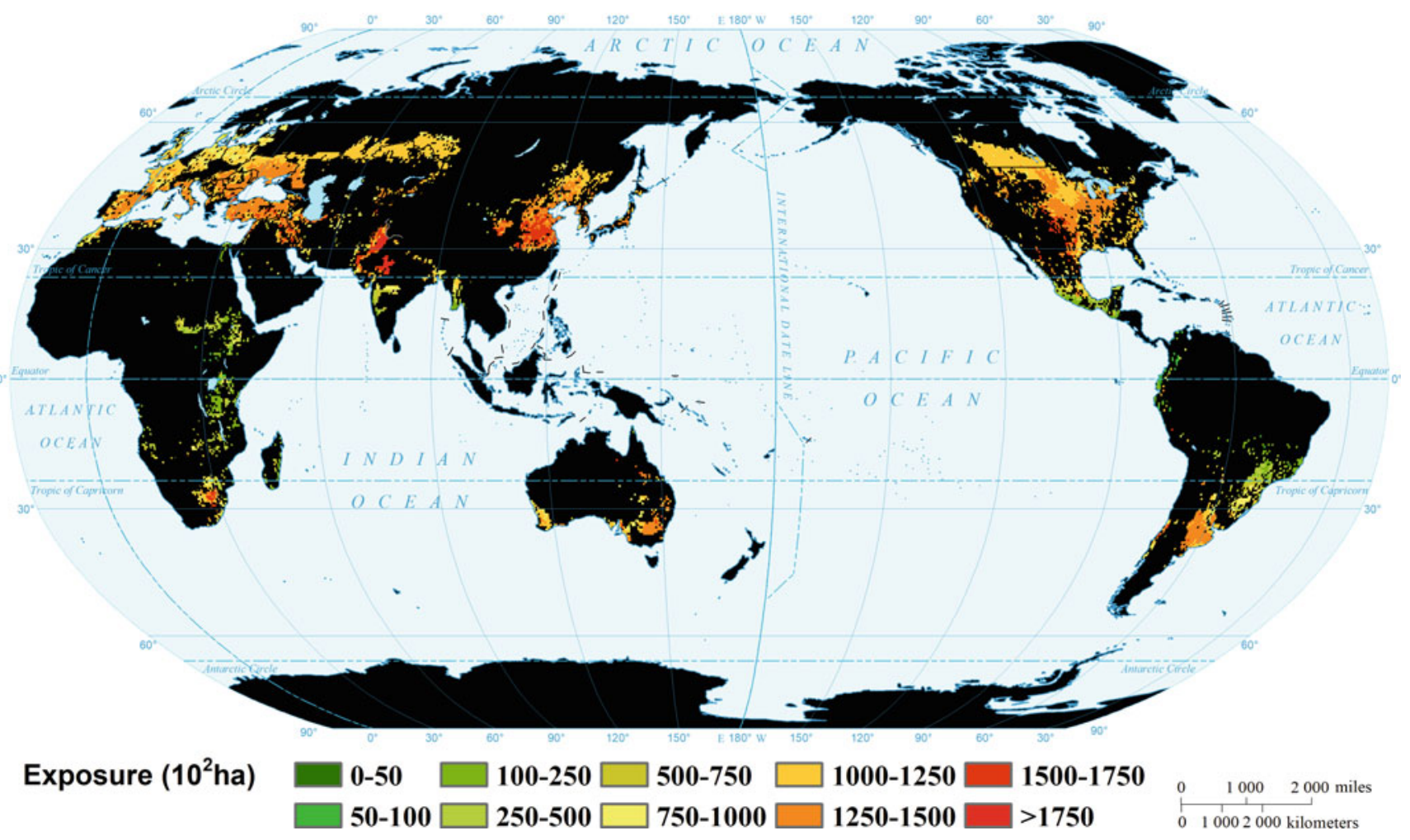


Global wheat exposure to extremely high temperature (2050s, RCP4.5-SSP2)

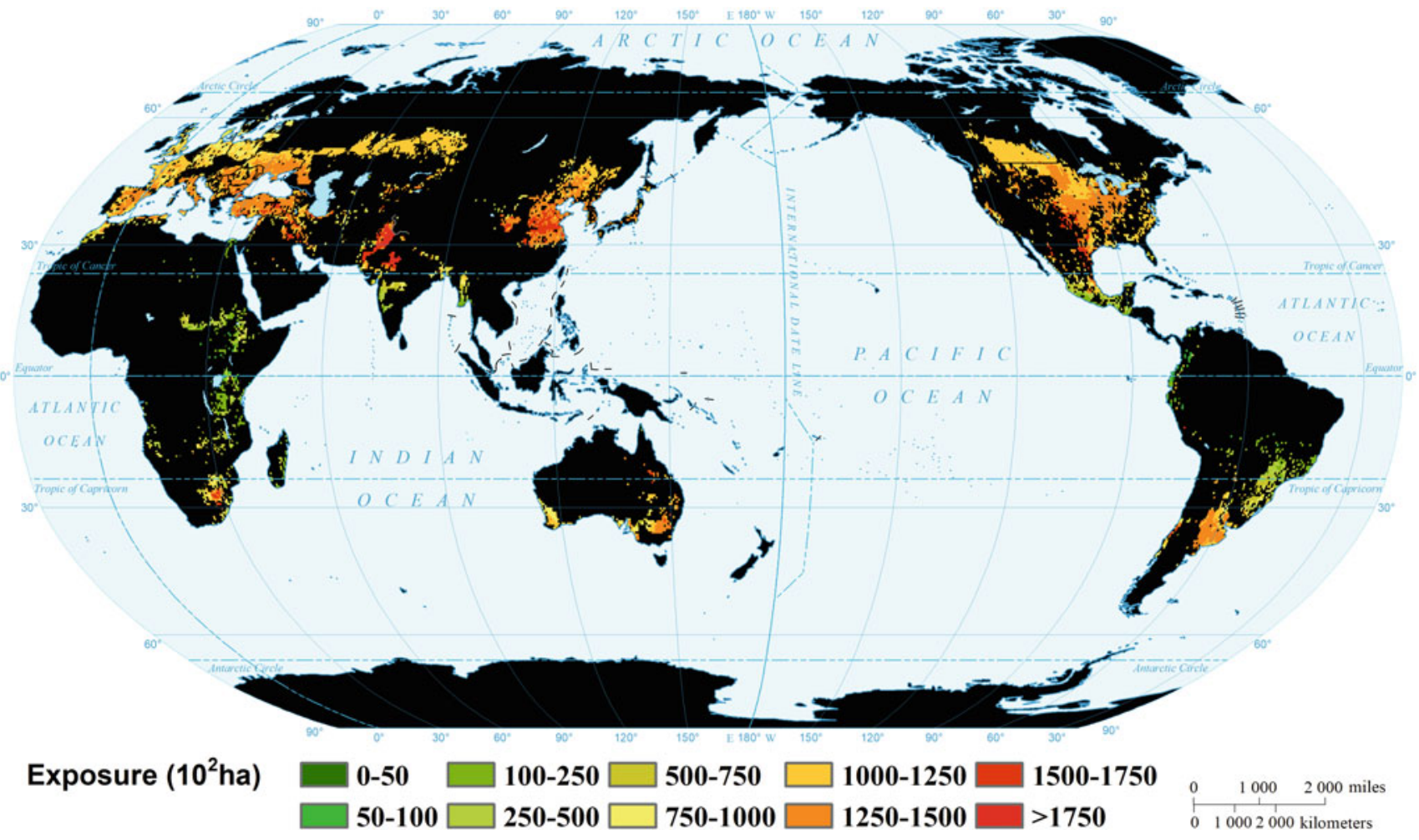

Global wheat exposure to extremely high temperature (2050s, RCP8.5-SSP3)

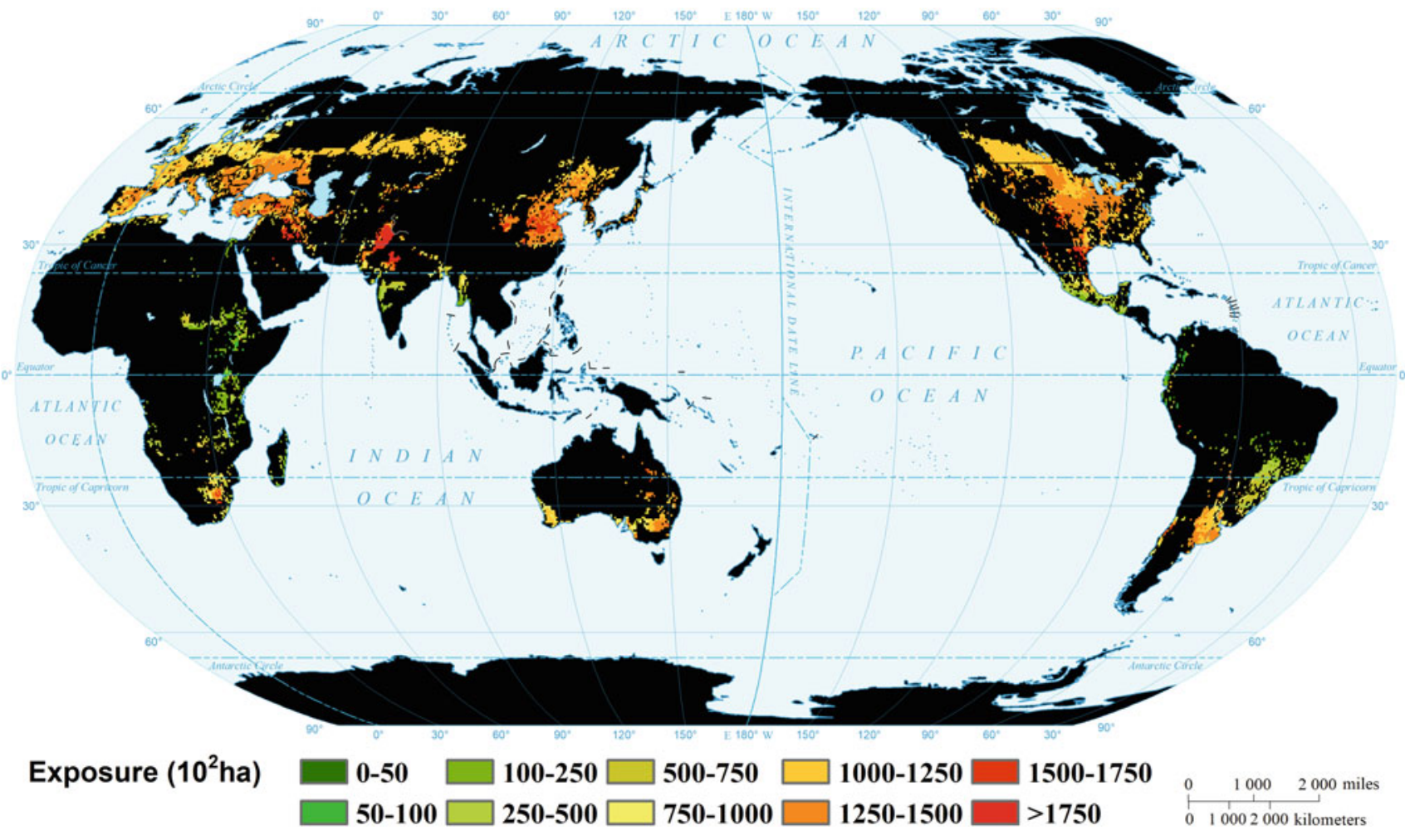




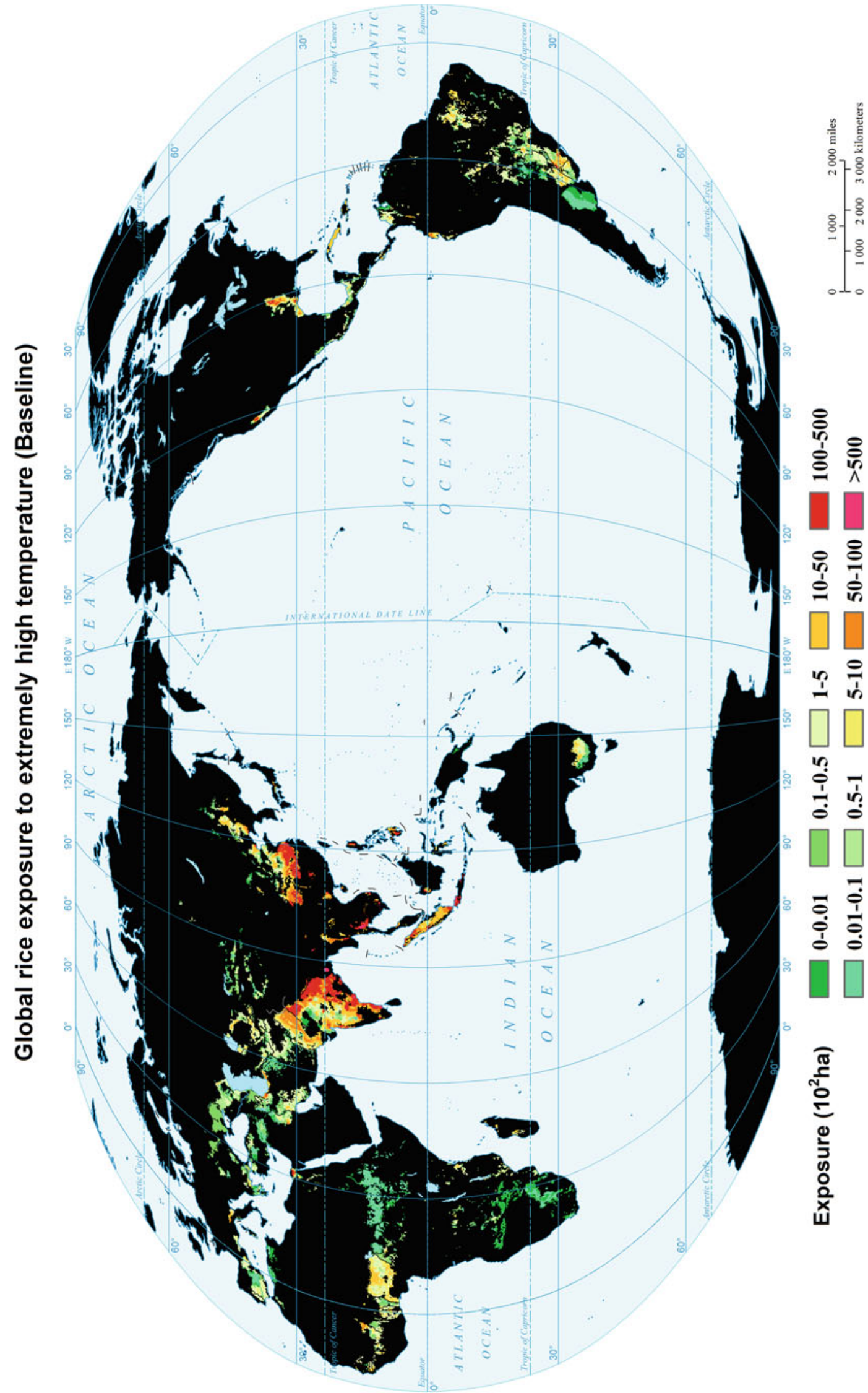


Global rice exposure to extremely high temperature (2030s, RCP2.6-SSP1)

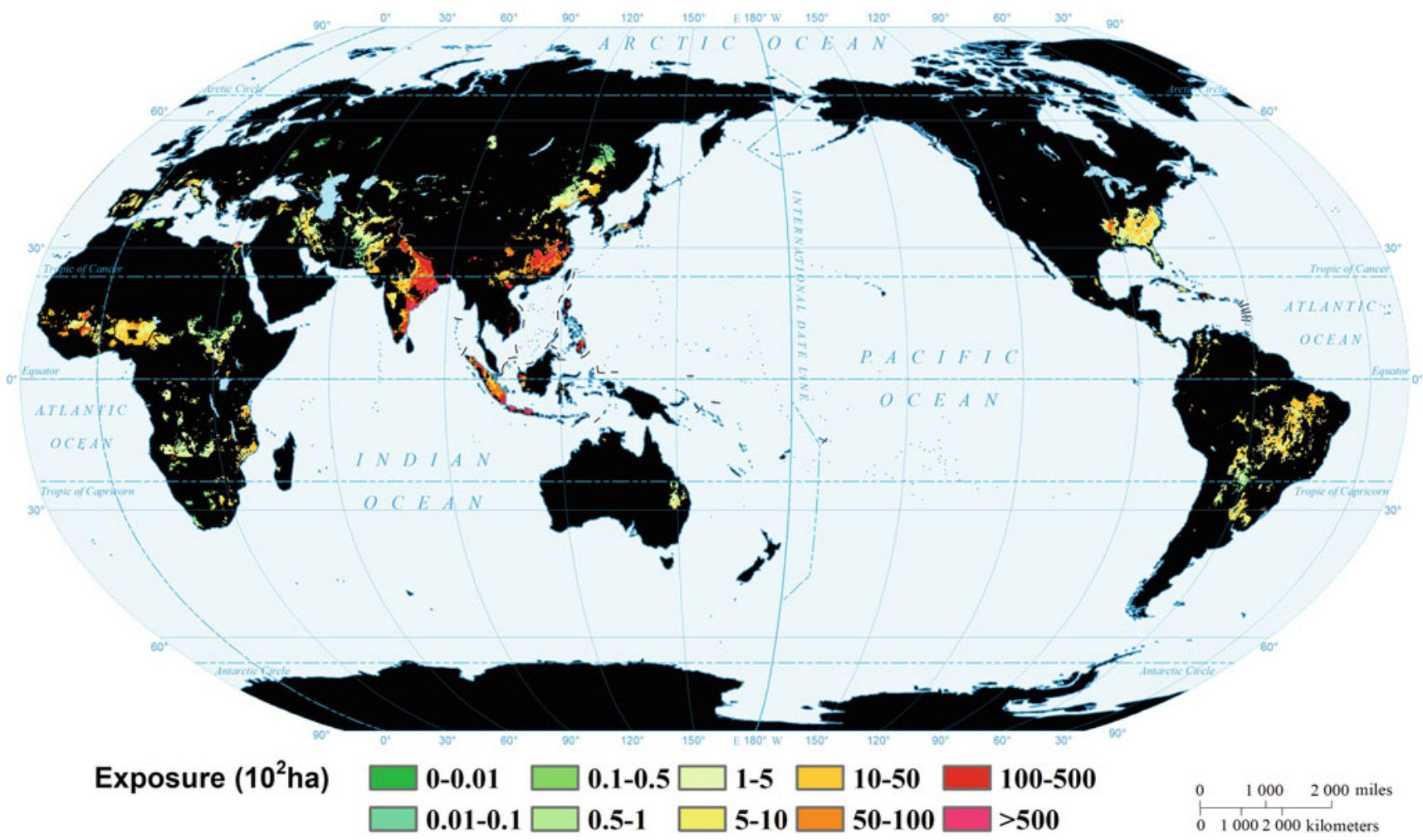

Global rice exposure to extremely high temperature (2030s, RCP4.5-SSP2)

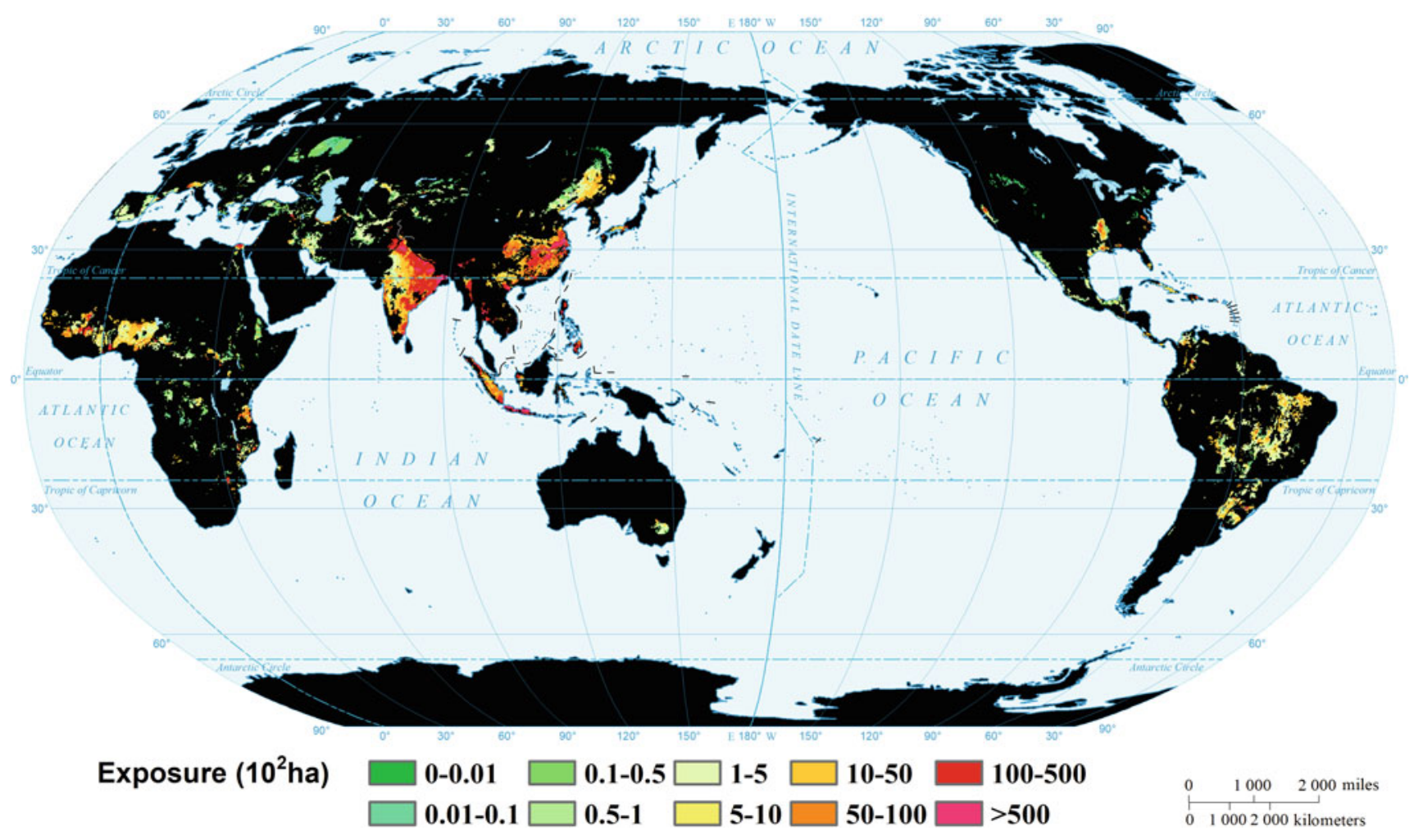


Global rice exposure to extremely high temperature (2030s, RCP8.5-SSP3)

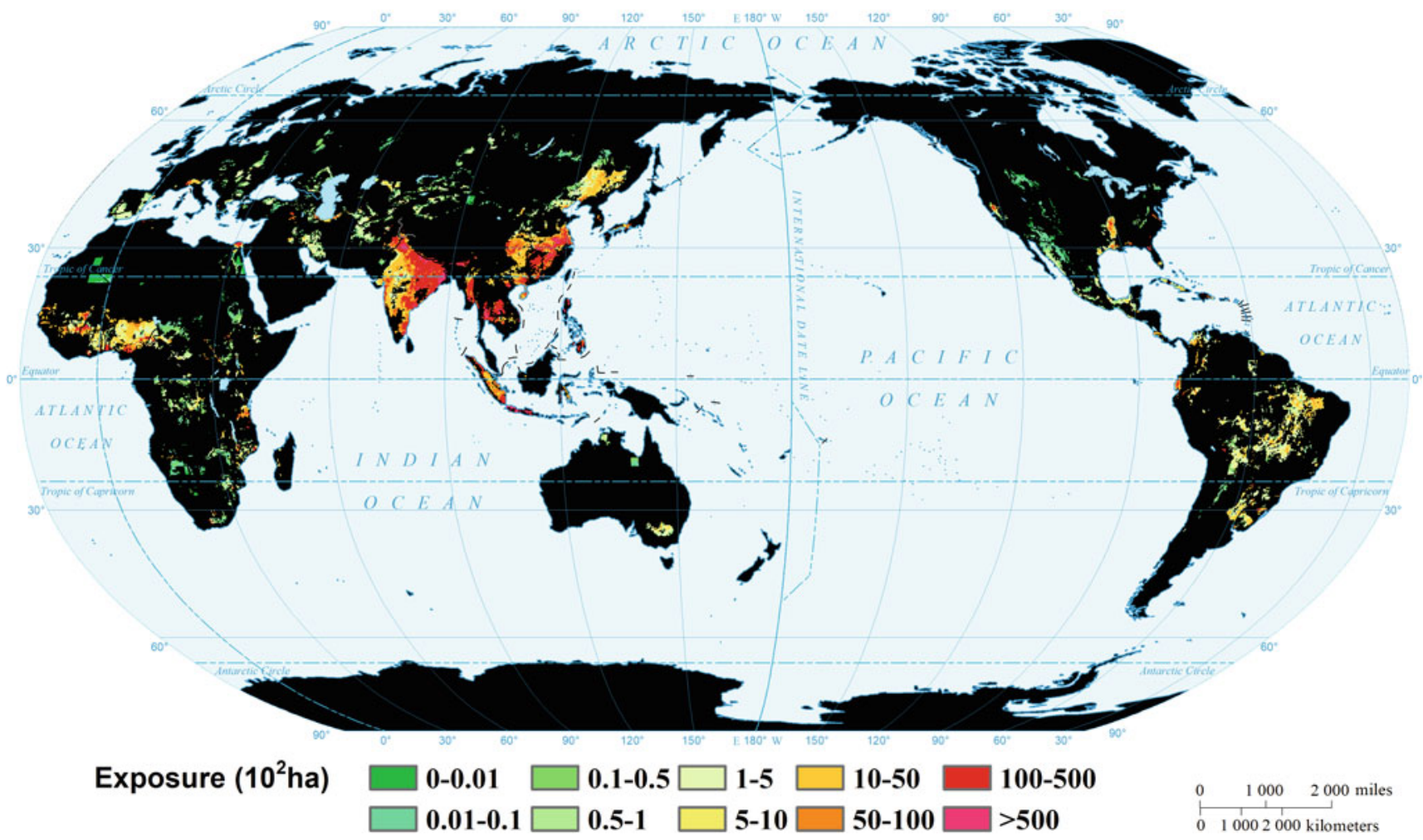

Global rice exposure to extremely high temperature (2050s, RCP2.6-SSP1)

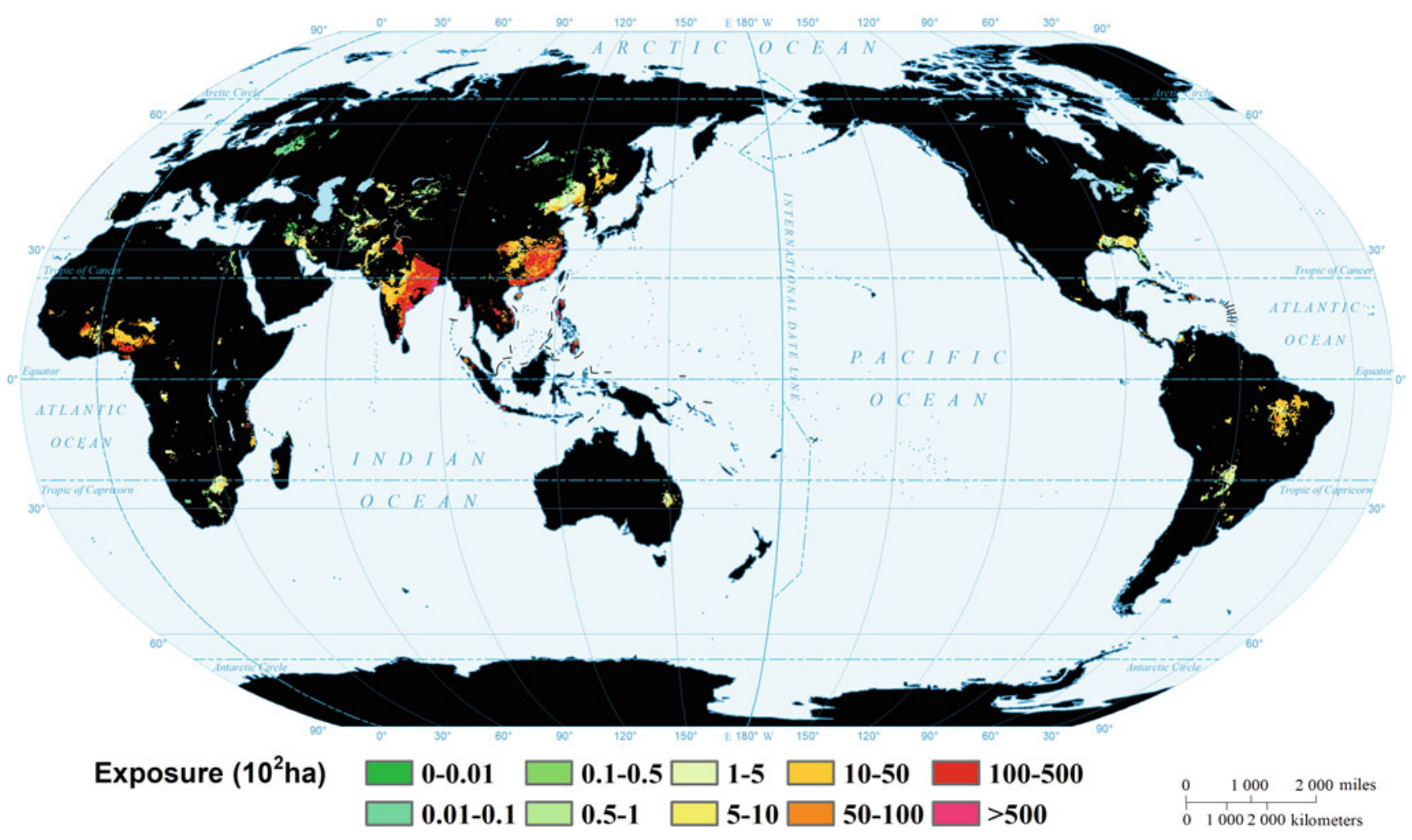


Global rice exposure to extremely high temperature (2050s, RCP4.5-SSP2)

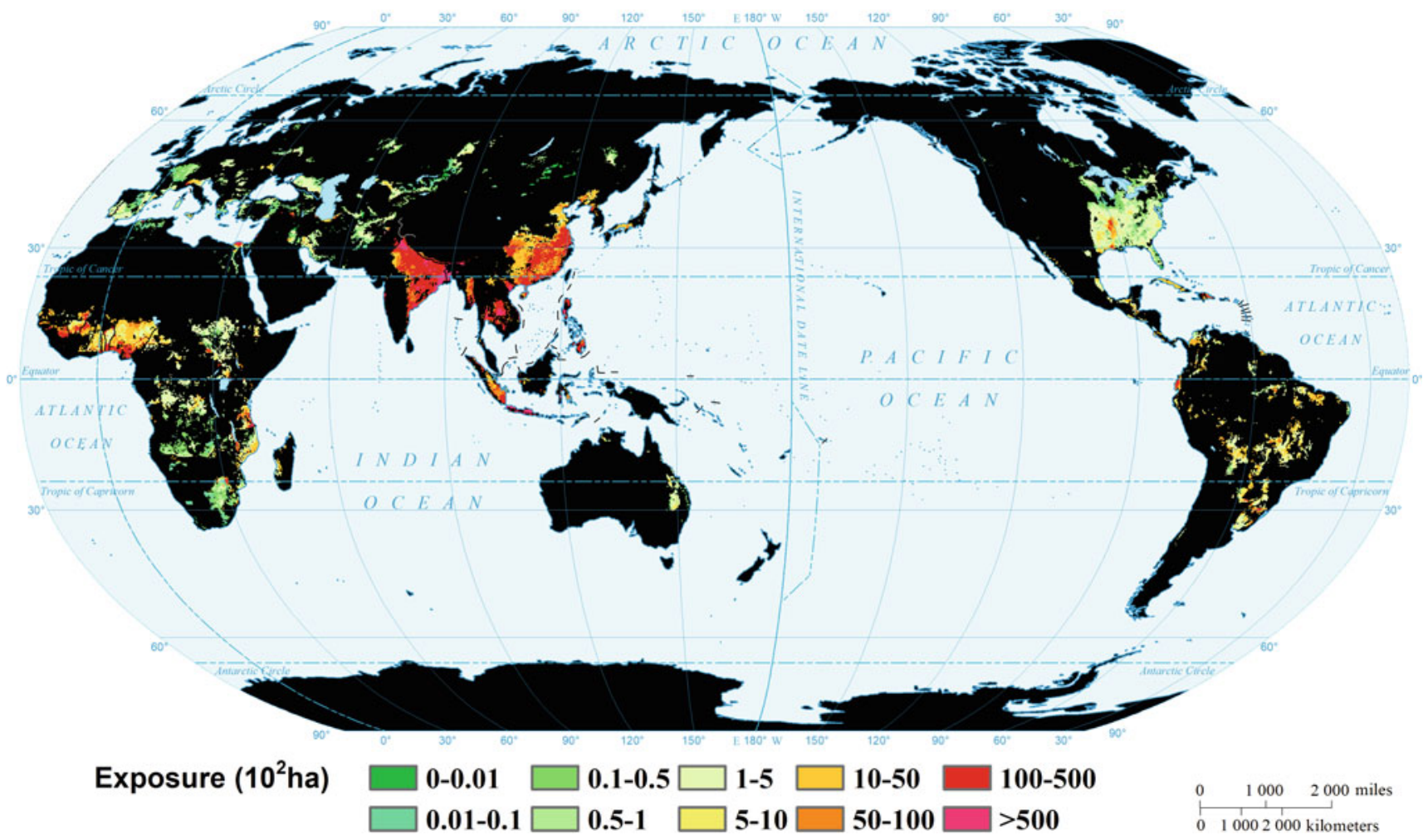

Global rice exposure to extremely high temperature (2050s, RCP8.5-SSP3)

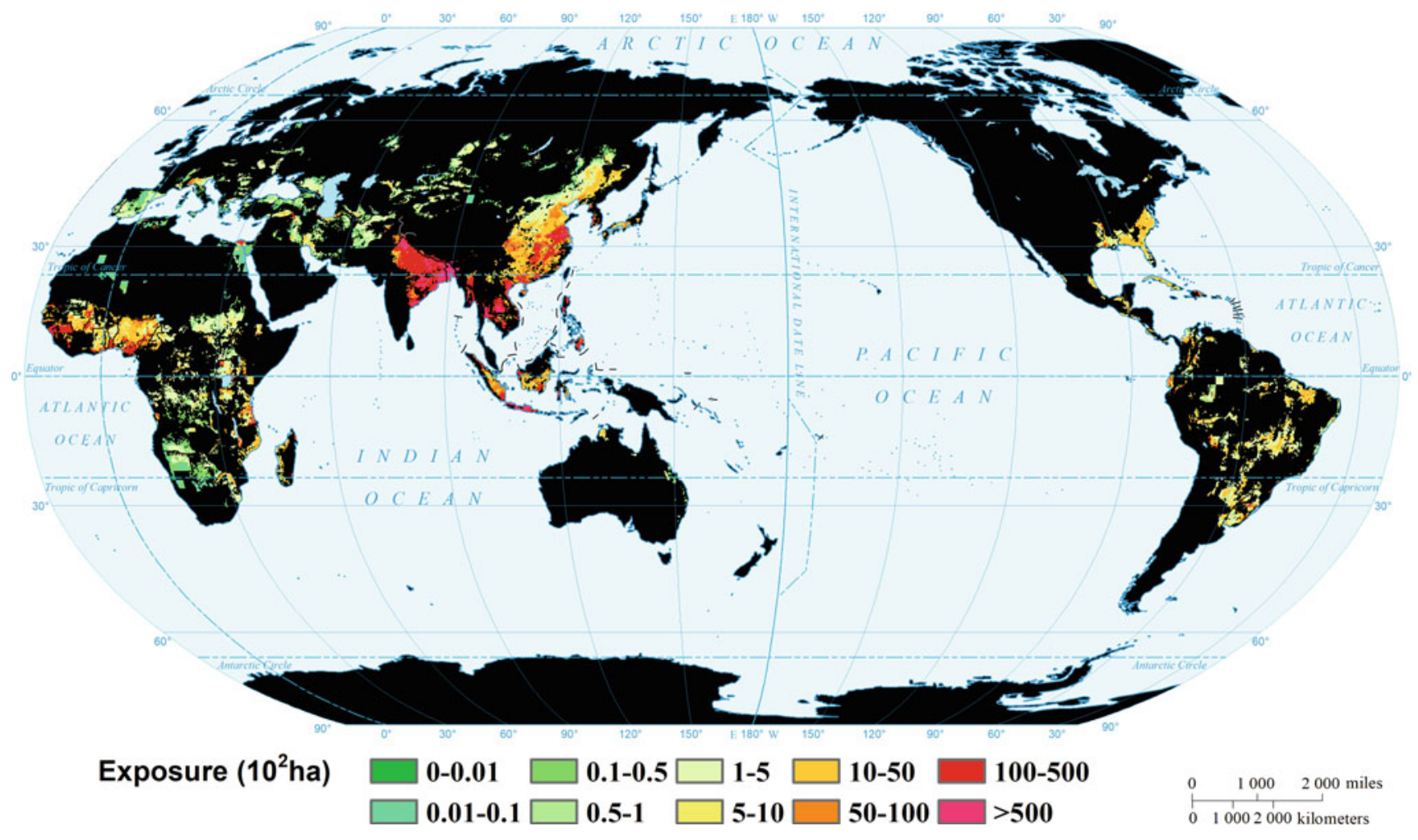




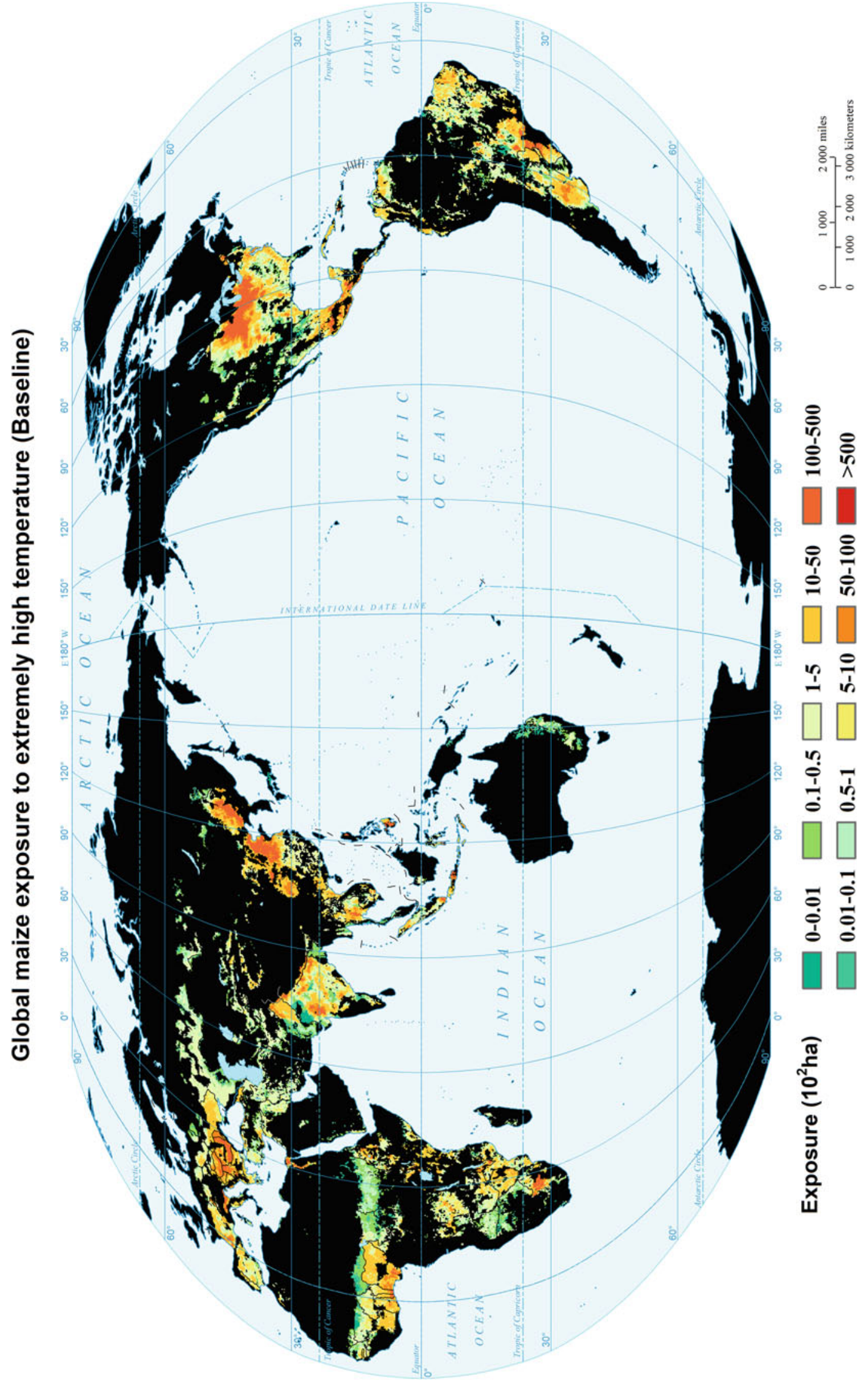


Global maize exposure to extremely high temperature (2030s, RCP2.6-SSP1)

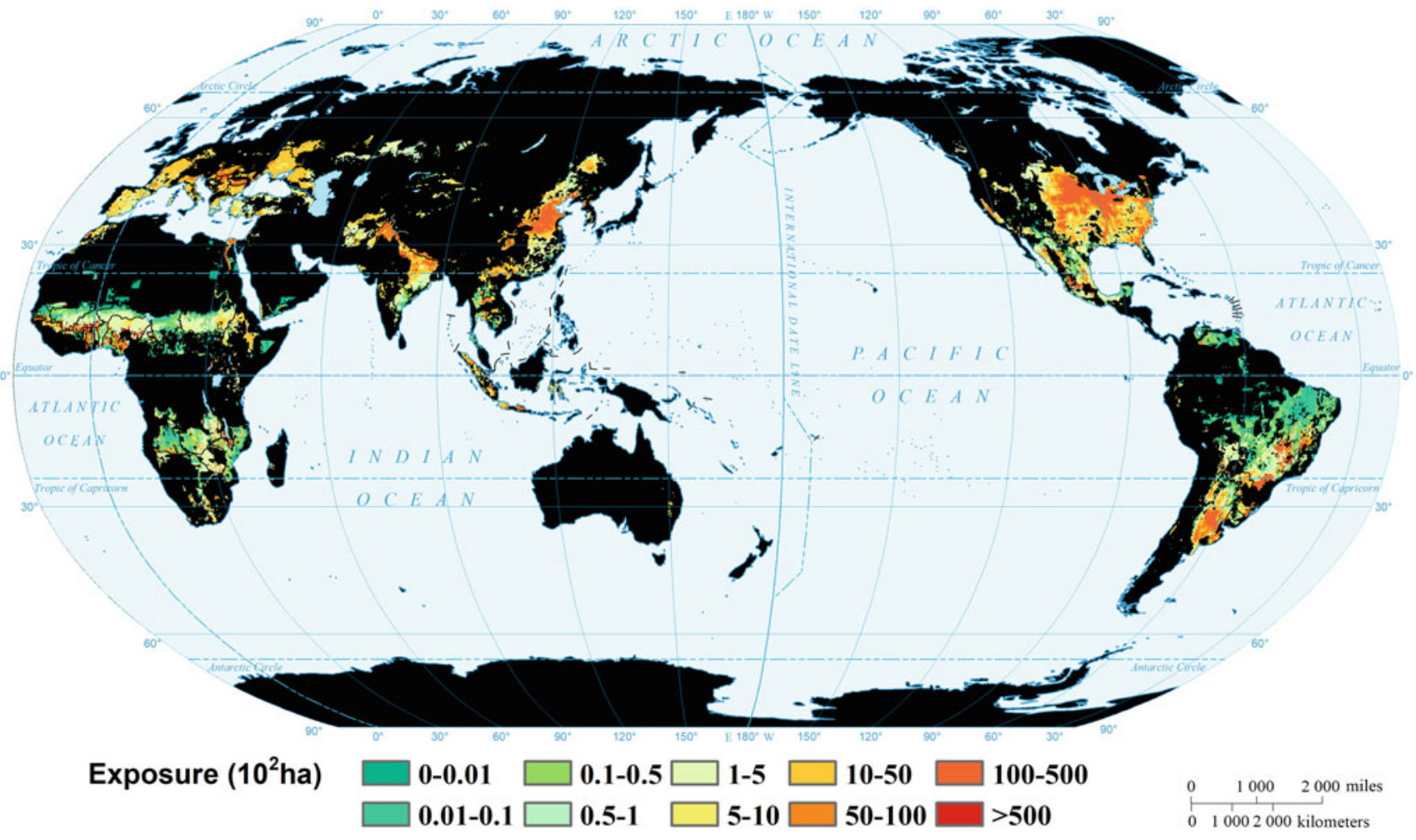

Global maize exposure to extremely high temperature (2030s, RCP4.5-SSP2)

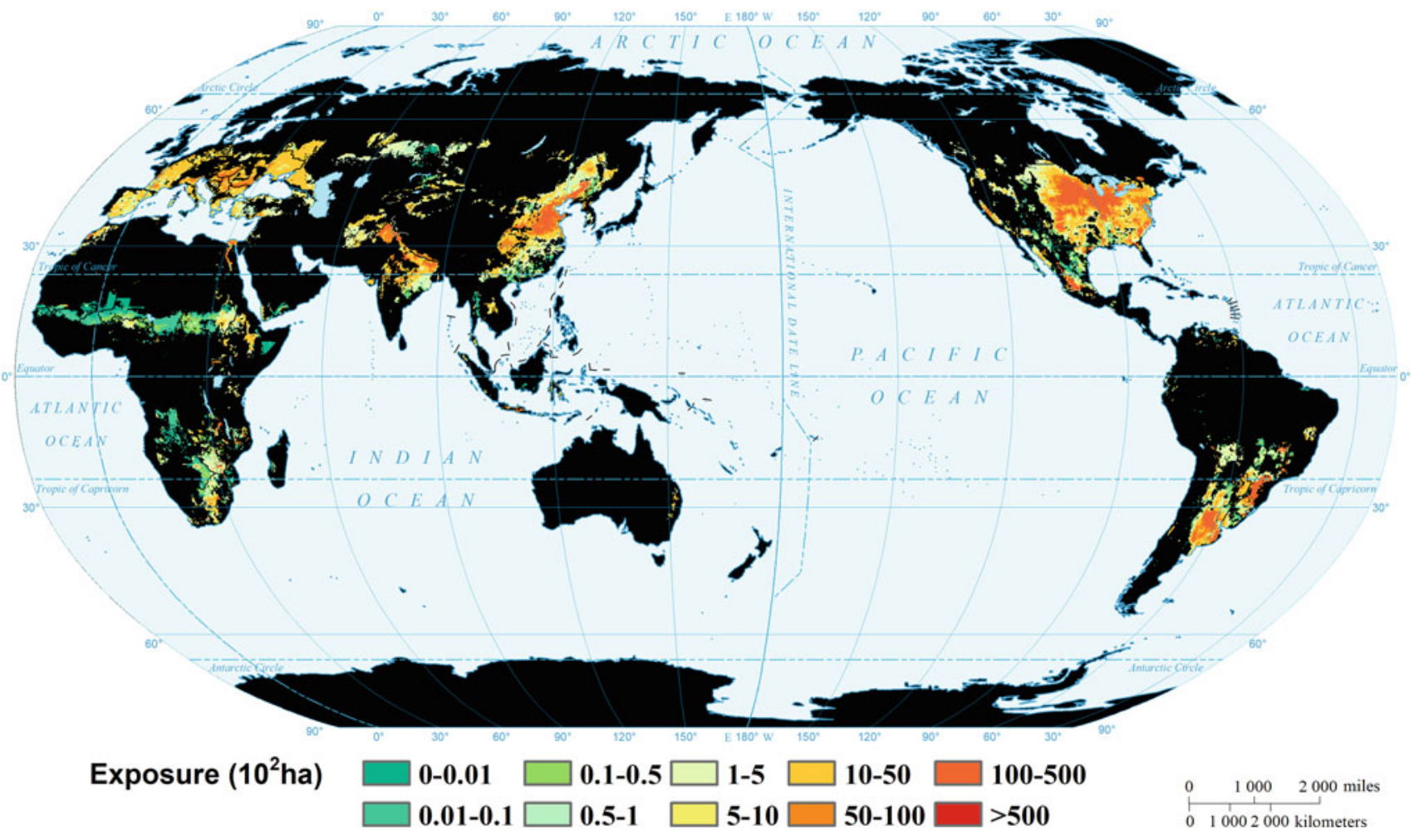


Global maize exposure to extremely high temperature (2030s, RCP8.5-SSP3)

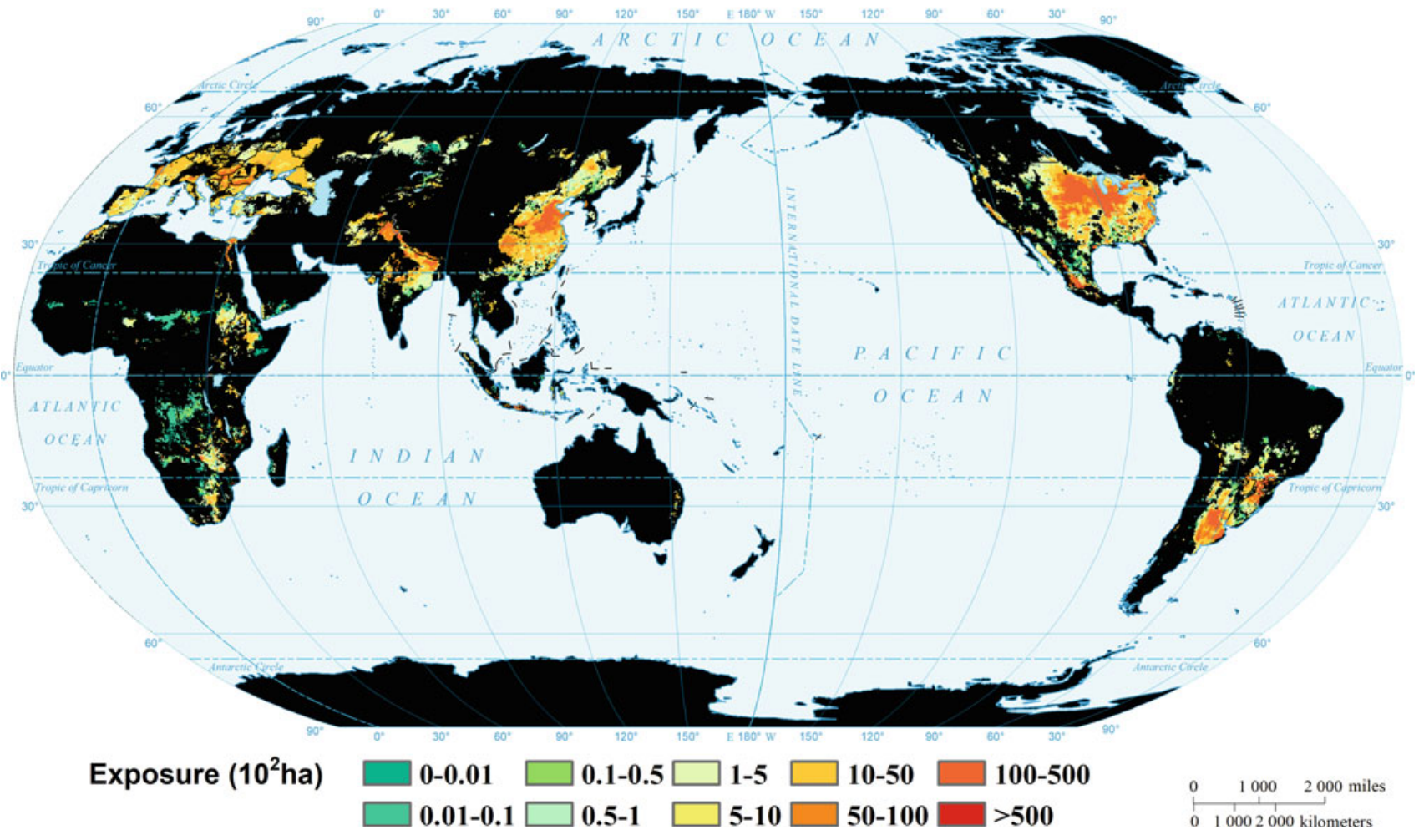

Global maize exposure to extremely high temperature (2050s, RCP2.6-SSP1)

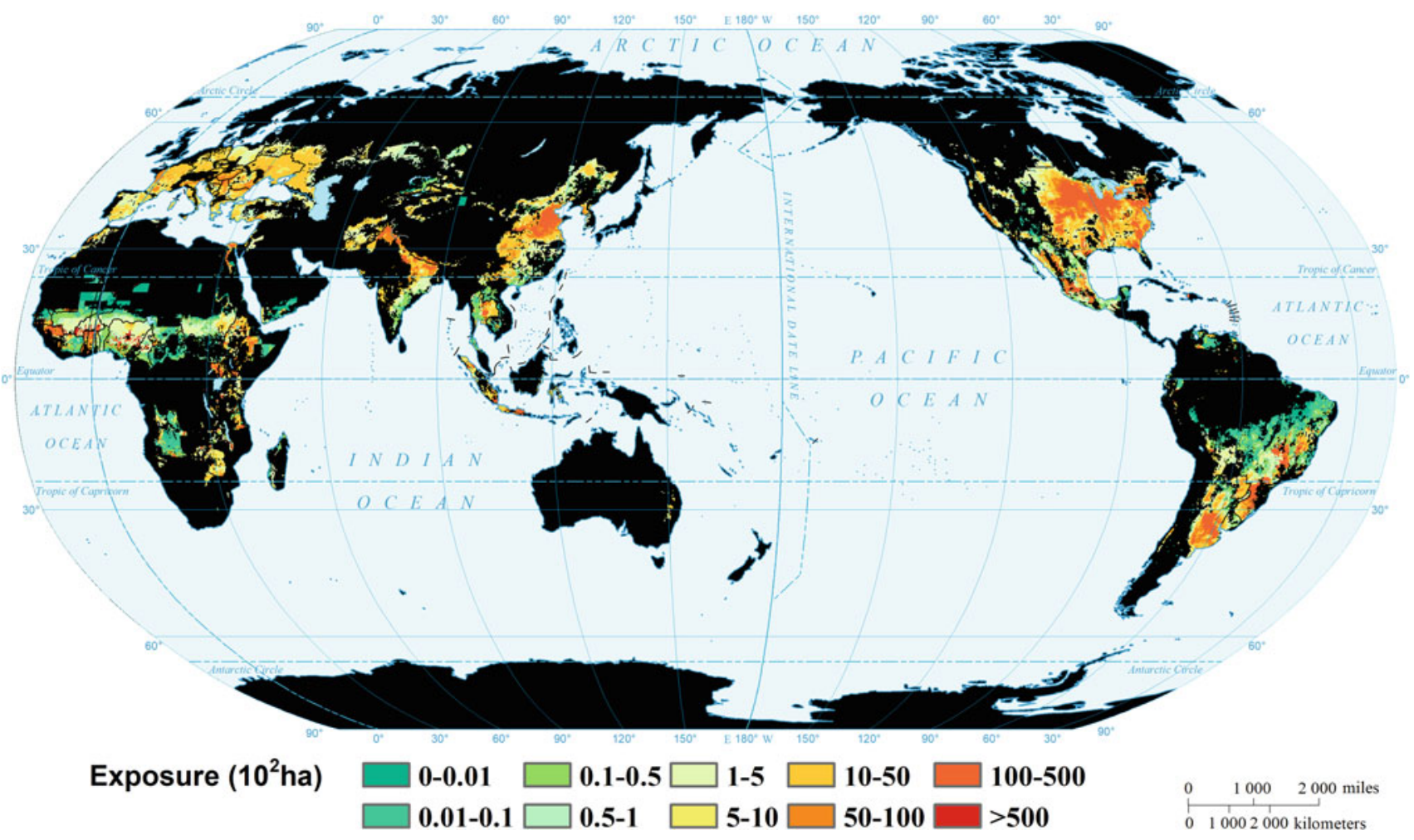


Global maize exposure to extremely high temperature (2050s, RCP4.5-SSP2)

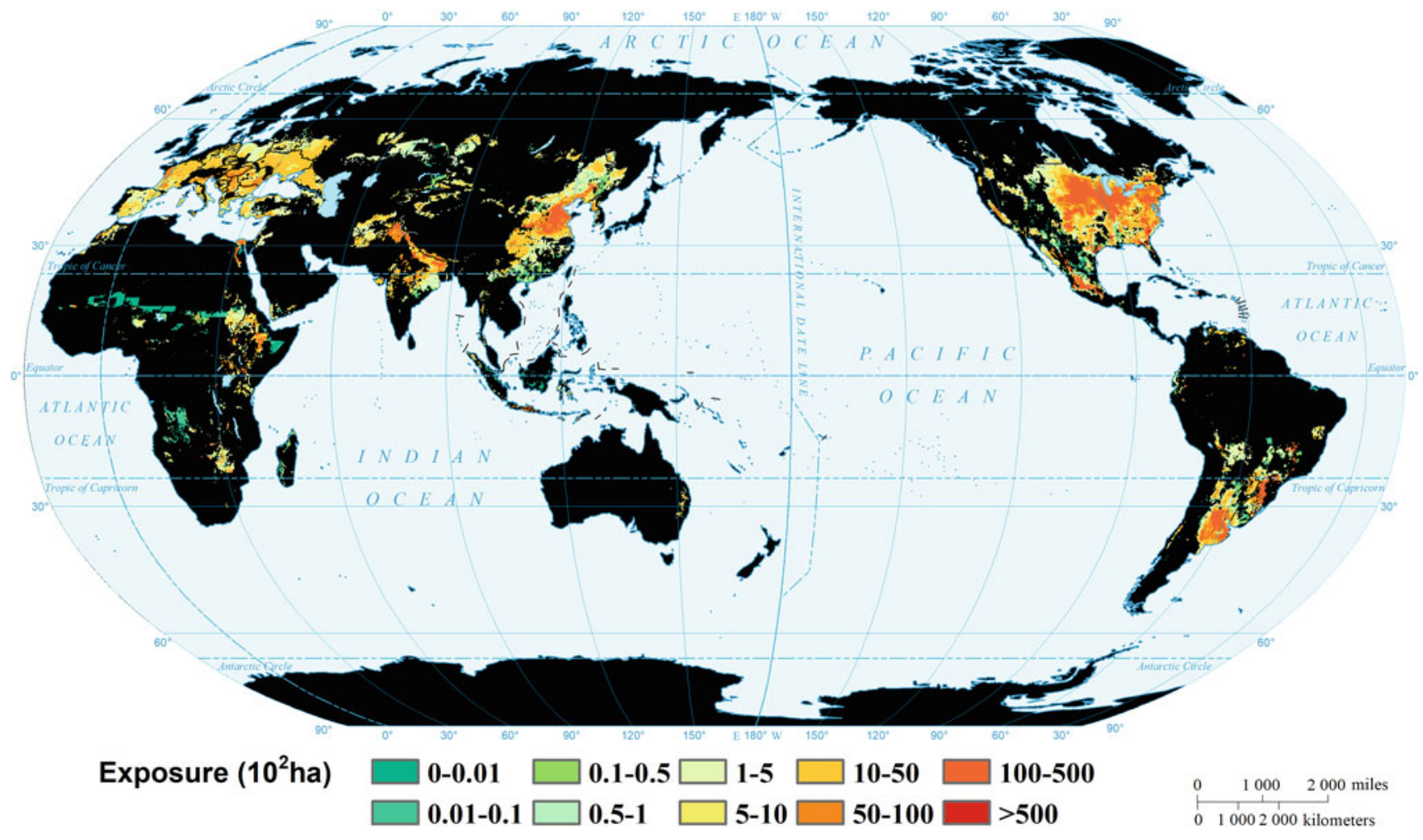

Global maize exposure to extremely high temperature (2050s, RCP8.5-SSP3)

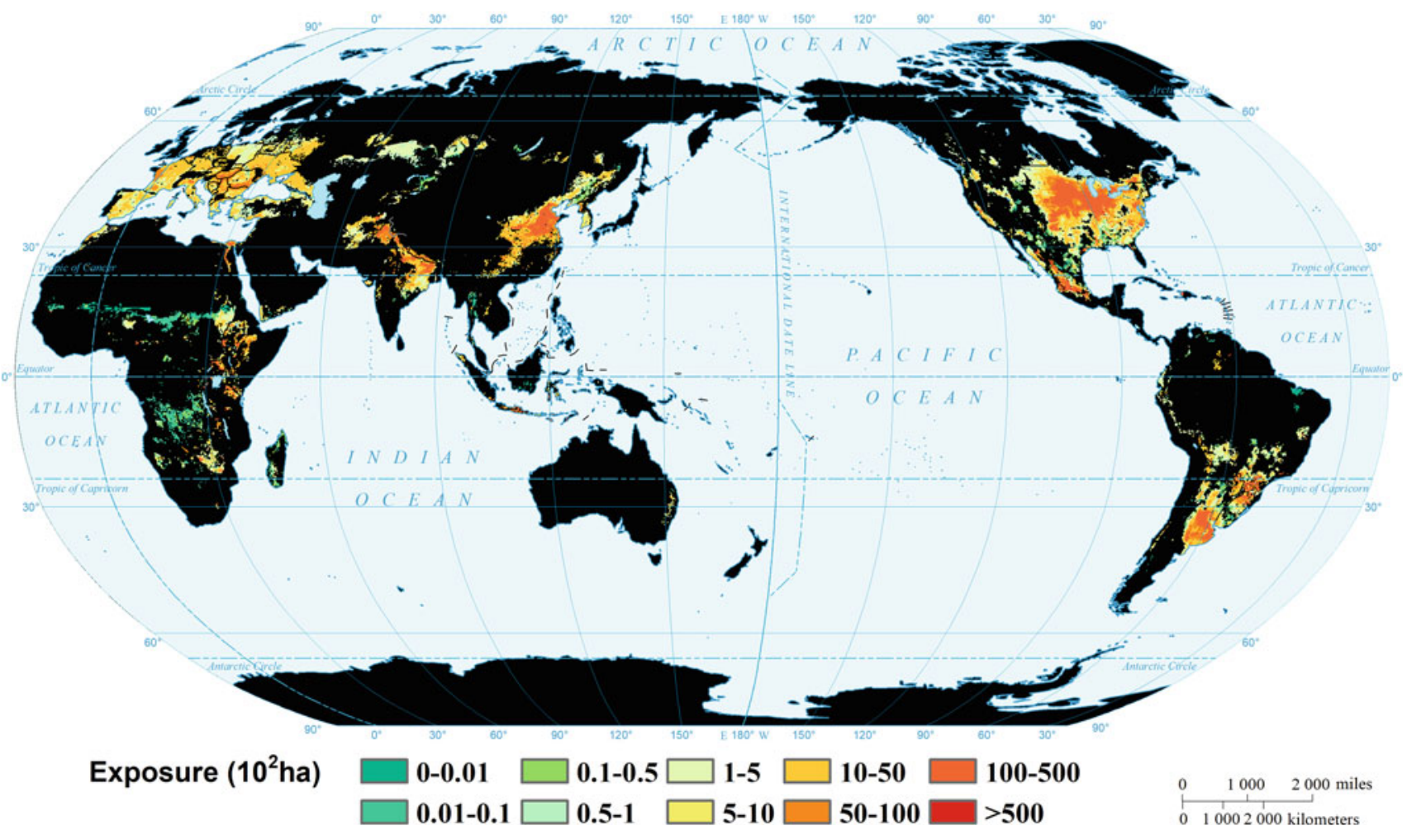




\section{References}

Change, P. C. (2018). Global wWarming of $1.5^{\circ}$ C. Geneva: World Meteorological Organization, Geneva, Switzerland, 10.

Chen, Y., Z. Zhang, and Z., P. Wang, P., X. Song, X., X. Wei, X., \& and F. Tao., F. . 2016. Identifying the impact of multi-hazards on crop yield-A case for heat stress and dry stress on winter wheat yield in northern China. European Journal of Agronomy 73: 55-63.

Deng, Z.Y., J.F, Xu., and L.N, Huang. (2009). Research Summary of the Damage Characteristics of the Wheat Dry Hot Wind in Northern China. Journal of Anhui Agricultural Sciences, 20.

Fahad, S., Adnan, M., Hassan, S., Saud, S., Hussain, S., Wu, C., Wang, D., Hakeem, K.R., Alharby, H.F., Turan, V. and Khan, M.A., 2019. Rice responses and tolerance to high temperature. In Advances in rice research for abiotic stress tolerance (pp. 201-224). Woodhead Publishing.

Holzkämper, A., P. Calanca, and J. Fuhrer. 2012. Statistical Crop Models: Predicting the Effects of Temperature and Precipitation Changes. Climate Research 51 (1): 11-21. https://doi.org/10.3354/ cr01057.

Iizumi, Toshichika, and Navin Ramankutty. 2016. "Changes in Yield Variability of Major Crops for 1981-2010 Explained by Climate Change.” Environmental Research Letters 11 (3). https://doi.org/10. 1088/1748-9326/11/3/034003.

Janetos, A. C. (1997). Climate Cchange 1995: Impacts, Aadaptations and Mmitigation of Cclimate Cchange: Scientific-Ttechnical Aanalyses.: JSTOR.

Jiang, Q., Y. Yue, and Y., \& and L. Gao., L. . 2019. The spatial-temporal patterns of heatwave hazard impacts on wheat in northern China under extreme climate scenarios. Geomatics, Natural Hazards and Risk 10 (1): 2346-2367.

Lobell, D.B., and M.B. Burke. 2010. On the use of statistical models to predict crop yield responses to climate change. Agricultural and Forest Meteorology 150 (11): 1443-1452.

Melillo, J., J. Borchers, J., J. Chaney, J., H. Fisher, H., S. Fox, S., A. Haxeltine, A. Janetos, D.W. Klicklighter, A. et al., . . McGuire, A. (1995). Vegetation/ecosystem modeling and analysis project: Comparing biogeography and biogeochemistry models in a continental-scale study of terrestrial ecosystem responses to climate change and $\mathrm{CO}_{2}$ doubling. Global Biogeochemical Cycles 9(4): 407--438.

Osborne, T.M., and T.R. Wheeler. 2013. Evidence for a Climate Signal in Trends of Global Crop Yield Variability over the Past 50 Years. Environmental Research Letters 8 (2): 024001. https://doi.org/10. 1088/1748-9326/8/2/024001.

Oyebamiji, Oluwole K., Neil R. Edwards, Philip B. Holden, Paul H. Garthwaite, Sibyll Schaphoff, and Dieter Gerten. 2015. Emulating Global Climate Change Impacts on Crop Yields. Statistical Modelling $15 \quad$ (6): 499-525. https://doi.org/10.1177/ 1471082 X 14568248.

Peng, S., J. Huang, J. E., Sheehy, J. E., R.C. Laza, R. C., R.M. Visperas, R. M., X. Zhong, G.S. Centeno, G.S. Khush, and K. G. Cassman. 2004. Rice yields decline with higher night temperature from global warming. Proceedings of the National Academy of Sciences 101 (27): 9971-9975.

Raimondo, Maria, Concetta Nazzaro, Giuseppe Marotta, and Francesco Caracciolo. 2020. Land Degradation and Climate Change: Global Impact on Wheat Yields. Land Degradation \& Development. https://doi.org/10.1002/ldr.3699.
Open Access This chapter is licensed under the terms of the Creative Commons Attribution 4.0 International License (http:// creativecommons.org/licenses/by/4.0/), which permits use, sharing, adaptation, distribution and reproduction in any medium or format, as long as you give appropriate credit to the original author(s) and the source, provide a link to the Creative Commons license and indicate if changes were made.
The images or other third party material in this chapter are included in the chapter's Creative Commons license, unless indicated otherwise in a credit line to the material. If material is not included in the chapter's Creative Commons license and your intended use is not permitted by statutory regulation or exceeds the permitted use, you will need to obtain permission directly from the copyright holder. 